\title{
EXISTE DIREITO INTERNACIONAL EM ROUSSEAU?
}

Arlei de Espíndola ${ }^{1}$

\begin{abstract}
Resumo:
O artigo busca mostrar a presença da discussão sobre o problema do direito internacional na filosofia de Rousseau ainda que ele priorize a fundamentação dos princípios, no que consegue concluir de seu projeto, das relações estabelecidas no Estado, visando definir, teoricamente, a legitimidade do poder político internamente. Entretanto, mantém que estava na sua agenda refletir da mesma forma sobre as relações ideais entre os povos à medida que os acontecimentos bélicos de sua época, no mundo europeu, cobravam por isto. Se a escrita do genebrino fornece elementos para dizer-se que a unidade natural é a referência nos começos, ir adiante, com o propósito de pensar sobre o direito internacional, tendo em conta aquilo que a ele se relacionava, admitindo, pois, a existência de outros Estados, permanentemente em contato, é o que precisaríamos aceitar. São as desavenças, estabelecidas e consumadas, neste âmbito mais amplo, que se apresentavam ao final para serem administradas, fazendo-se correto dar atenção a esse aspecto, germinal na obra de Rousseau, compreendendo-o com o valor por este merecido, assim como se procura fazer.
\end{abstract}

Palavras-chaves: Direito político. Direito internacional. Guerra. Paz. Justiça.

\section{IS THERE AN INTERNATIONAL LAW IN ROUSSEAU?}

\begin{abstract}
:
This article intends to show the presence of the discussion on the problem of international law in Rousseau's philosophy even though he prioritizes the groundings of principles, as he succeeds to conclude from his project, of the relations established in the State, aiming to define, theoretically, the legitimacy of the political power, internally. However, he sustains that it was on his agenda to reflect in the same way on ideal relations among peoples as warlike events of that time, in the European world, demanded for this. If the Genevan's writings provide elements in order to say that the natural unity is the reference in the beginnings, to go forward with the purpose of thinking about the international law, considering what was related to him, thus admitting the existence of other States, permanently in touch, is what we would need to accept. Established and consummate disagreements, in this broader scope, were presented at the end to be managed, being correct to pay attention to this aspect, germinal in Rousseau's work, understanding it with the value it deserves, as it is intended to be done.
\end{abstract}

Keywords: Political Law. International Law. War. Peace. Justice.

Partimos da questão de saber se existe direito internacional na reflexão desenvolvida por Rousseau. Ao nosso ver, pensar isto requer que se considere, sobretudo, o Do contrato social ou princípios do direito político (1762). Não raro o público leitor tem este trabalho como o grande livro do filósofo genebrino onde ele desenvolve sua meditação e teses mais profundas sobre filosofia política. Mas o que

1 Doutor em Filosofia pela Universidade Estadual de Campinas - UNICAMP/SP, com estágio pós-doutoral em Filosofia na Pontifícia Universidade Católica do Rio Grande do Sul - PUC/RS. Professor Associado do Departamento de Filosofia da Universidade Estadual de Londrina - UEL/PR. Com experiência na Graduação e Pós-Graduação (Strictu Sensu), tendo orientado em nível de mestrado. E-mail: earlei@uel.br 
vem a ser o Contrato social exatamente? É um texto exaustivo, completo, em que o pensador explora ao extremo sua pesquisa esgotando todas suas possibilidades? Veja-se sua "Nota de advertência", da edição originária, em que sinaliza que se resignar a organizá-lo e imprimi-lo foi consequência de não haver pesado melhor suas forças e condições quando definiu sua meta no começo de todo o percurso:

\footnotetext{
Este pequeno tratado foi extraído duma obra mais extensa, outrora iniciada sem que houvesse consultado minhas forças e de há muito abandonada. Dos vários trechos que se podiam tomar ao que estava feito, este é o mais considerável e pareceu-me o menos indigno de ser oferecido ao público. $\mathrm{O}$ resto não mais existe (OC III, Du contrat social, 1964, p. 349).
}

O fragmento atesta, sem entrar no aspecto da densidade conceitual, obscuridades, hermetismo, e contradições, que Rousseau tem o Contrato social enquanto um trabalho modesto, acanhado, com limitações, que fazia parte de algo maior, sendo o que sobreviveu por trazer conteúdo que valeria ser levado ao conhecimento público. Ele não informa, ainda, que saber é este contido nos trechos preservados do projeto, mas que vai importar a nós descobrirmos.

Rousseau é um especulador diferente que costuma nos ajudar a interpretar sua vasta obra, pois a comenta com um grau considerável de isenção e neutralidade. Por certo a política sempre o interessou, e ele identificou sua presença entremeada a todas as coisas desde cedo. Mas há um relato do livro IX de As confissões que é importante para compreendermos o valor que Rousseau passou, desde um determinado momento, a atribuir à política, sendo motivado pelos acontecimentos, reconhecendo a relação de dependência que existe entre a natureza de um governo e o caráter de um povo, entre este primeiro e a lei; o momento, enfim, do despertar do interesse que desenvolveu propriamente, digamos, pelo direito político. Neste quadro remissivo o autor nos dá a oportunidade de entender o significado de suas Instituições políticas, esta obra maior à que se dedicava, da qual resultou o Contrato social, e que terminou interrompendo a escrita por julgar se tratar de um projeto complexo demais que o fazia avançar vagarosamente em sua consumação. É a partir desta grande obra, cujos passos iniciais foram gestados e estabelecidos durante o período em que trabalhou como secretário da embaixada francesa em Veneza, entre os anos de 1743-1744, que estas ideias acima lembradas, juntamente com outras tantas que muito importavam à felicidade do gênero humano, ganharam importância na reflexão do autor. Agora de

\begin{tabular}{|l|l|l|l|l|}
\hline Gevista Dialectus & Ano 8 & n. 15 & Agosto-Dezembro 2019 & p.54-71 \\
\hline
\end{tabular}


suas Instituições políticas Rousseau imaginava se beneficiar extraindo grande proveito enquanto pensador, embora temesse a ousadia e pioneirismo nele marcados no ambiente sócio-político e cultural onde se inseria, ambiente onde vigorava o despotismo, o arbítrio, a violência, a insensibilidade, faltando, da parte de uns, o saber mais fino, etc.:

Das várias obras que tinha na gaveta, aquela sobre a qual mais meditava, que mais gosto me dava e na qual quereria trabalhar a vida inteira e que devia, segundo eu achava, coroar minha reputação, eram minhas Institutions politiques. Havia treze ou quatorze anos que me tinha ocorrido a primeira ideia, quando, estando em Veneza, tinha tido ocasiões de observar os defeitos daquele tão gabado governo. Desde então minhas vistas se haviam estendido muito no estudo histórico da moral. Vira que tudo se relacionava radicalmente com a política e que, de qualquer modo que o encarássemos, povo nenhum teria natureza diferente daquela que seu governo lhe emprestava; deste modo, esta grande questão sobre o melhor governo possível parecia reduzir-se a esta: Qual a natureza de governo indicada para formar o povo mais virtuoso, mais esclarecido, mais sábio, enfim, o melhor, tomando esta palavra no seu mais amplo sentido? Julgava perceber que esta questão muito se relacionava com esta outra abaixo, se é que era diferente: Qual o governo que, por sua natureza, se mantém sempre mais próximo da lei? Donde o que é a lei? E uma série de perguntas da mesma importância. Via que tudo isto me levava a grandes verdades, úteis à felicidade do gênero humano, porém principalmente à da pátria, onde eu não havia encontrado, na viagem que acabava de fazer, noções sobre leis e liberdade tão justas quanto nítidas, segundo meu parecer; e tinha pensado naquela maneira indireta de lhes dar as mais indicadas para que aproveitassem o amor-próprio de seus membros e conseguindo que me perdoassem por ter visto no assunto um pouco mais longe do que eles (OC I, Les confessions, 1959, p. 404-405).

Rousseau reconhece dificuldades, complexidades, entraves, que envolvem a teoria que visa dar forma nas Instituições políticas que não indica ou demonstra aqui, pormenorizadamente, quais são exatamente, e que por isso o livro avançava de forma lenta. Admite que talvez ele nem pudesse sair do forno enquanto vivesse. Mas investia todas as suas energias e faculdades nele, não aceitava renunciar o direito de pensar, e até mantinha o projeto em segredo para garantir sua liberdade na execução, exigindo de si somente manter-se dentro da lei de seu país e no quadro do direito dos povos:

Apesar de fazer cinco ou seis anos que eu trabalhava nesta obra, ela ainda estava pouco adiantada. Livros desta espécie exigem meditação, vagar, tranquilidade. E mais, eu fazia este trabalho, como se diz, para o que desse e viesse, e não teria querido comunicar o meu projeto a ninguém, nem mesmo a Diderot. Receava que minha teoria parecesse muito ousada para o século e o país em que a escrevia e que o espanto de meus amigos me constrangesse em sua execução. Também não sabia se a faria a tempo e de maneira a poder ser publicada enquanto eu vivesse. Queria, sem constrangimento, dar ao assunto tudo o que ele de mim exigia; bem certo de que, não tendo gênio satírico e não querendo nunca procurar-lhe aplicação, sempre seria irrepreensível com toda justiça. Sem dúvida eu queria usar plenamente do direito de pensar, direito que tinha por nascimento, mas sempre respeitando o

\begin{tabular}{|l|l|l|l|l|}
\hline Q Revista Dialectus & Ano 8 & n. 15 & Agosto - Dezembro 2019 & p. 54 - 71 \\
\hline
\end{tabular}


governo sob o qual vivia, sem jamais desobedecer-lhe às leis; e, muito atento para não violar o direito das gentes, não queria, tão pouco, renunciar às suas vantagens por simples medo (OC I, Les confessions, 1959, p. 405).

A sequência do presente raciocínio do livro IX de As confissões é reservada por Rousseau para dizer o quanto se sente confortável na França para tornar pública suas ideias por meio de seus livros. Se o leitor está acostumado desde o Discurso sobre a desigualdade vê-lo enaltecer Genebra por seu republicanismo, aqui ele reverencia em partes o poder na França que não o tolhe em sua liberdade de pensamento, pelo menos enquanto ainda não viu o choque produzido por seus grandes livros na década de sessenta; tem-se aqui o momento inicial, preparatório, da escrita de suas Instituições políticas que não foram abandonadas. Por essa realidade, pela comodidade por ela trazida, Rousseau possui preferência por ficar na França, apesar de este desejo modificar-se em períodos isolados com o correr do tempo:

Confesso mesmo que estrangeiro e vivendo na França, achava minha posição muito favorável para ousar dizer a verdade; sabendo bem que, continuando, como eu queria, só imprimindo aquilo para que obtivesse permissão, não devia prestar contas a ninguém de minhas máximas e de sua publicação alhures. Ter-me-ia sentido com menos liberdade na própria Genebra onde, qualquer que fosse o lugar em que meus livros fossem impressos, o magistrado tinha direito de dar a última palavra sobre seu conteúdo. Esta consideração muito havia contribuído para me fazer ceder às instâncias de madame d'Épinay e renunciar ao projeto de ir estabelecer-me em Genebra. Sentia, como disse em Émile, que a menos que fosse homem de intrigas, quando se quer consagrar livros ao verdadeiro bem da pátria, não é preciso escrevê-los em seu seio (OC I, Les confessions, 1959, p. 406).

Neste momento Rousseau entende, notadamente, que a França ganha mantendo-o em paz em seu território, em seu domínio, escrevendo seus livros:

\begin{abstract}
O que fazia achar minha posição mais feliz era a persuasão em que estava de que o governo de França, sem me ver com bons olhos talvez, consideraria uma honra, senão o proteger-me, pelo menos deixar-me tranquilo. Era, ao que me parecia, um rasgo político bem simples e no entretanto bem justo, o de vangloriar-me do mérito de tolerar o que não se pode impedir; porque, se me tivessem expulso de França, que era tudo o que tinham o direito de fazer, nem por isso os meus livros deixariam de ser escritos, e talvez com menos descrição; ao passo que me deixando em paz, guardavam o autor como caução de suas obras, e mais, apagariam os preconceitos bem enraizados no resto da Europa, ao conquistarem reputação de ter respeito esclarecido pelo direito das gentes (Idem, ibidem).
\end{abstract}

É do aceite de que as Instituições políticas lhe pediam mais do que podia dar, no sentido de dedicação, que vem nascer o Contrato social, logo após renunciar o

\begin{tabular}{|l|l|l|l|l|}
\hline Q Revista Dialectus & Ano 8 & n. 15 & Agosto - Dezembro 2019 & p.54-71 \\
\hline
\end{tabular}


desenvolvimento integral, ali, do projeto em mente. Parece-nos importante trazer a narrativa, também do livro $\mathrm{X}$ de As confissões, que nos informa sobre isto que dissemos, fazendo reforçar-se a leitura:

Examinei o estado deste livro e achei que ele ainda precisava de vários anos de trabalho. Não tive a coragem de levá-lo e esperar que ficasse pronto para pôr em execução a minha ideia. Por isso, renunciando a esta obra, resolvi tirar dela o que podia tirar, e depois queimar o resto; e trabalhando com cuidado, sem interromper o de Émile, em menos de dois anos dei a última penada em Contrat social (Idem, p. 516).

\section{II}

Estas referências ao "pequeno tratado", ao Contrato social, somadas com a da acalentada Instituições políticas, preparam o terreno para entrarmos no tema "direito internacional em Rousseau", mas sem permitir pensar se há esta reflexão ou não estritamente no autor genebrino. Para tanto, temos talvez de nos perguntar sobre qual esfera o Contrato social, parte mais completa e de maior conhecimento público do que sobrou, abarcava do conjunto da pesquisa abandonada, mas projetada inicialmente nas Instituições políticas. E a resposta para essa pergunta aparece em dois pontos da escrita de Rousseau, pontos estes de extrema utilidade para levarmos adiante nossa presente investigação. Um é a da própria escrita do Contrato social cuja publicação deu-se em março de 1762. O livro, como sabemos, fragmento de um projeto filosófico maior, contendo 4 livros, mas fazendo-se um texto relativamente breve para os padrões dos grandes tratados clássicos, traz uma conclusão de $1 \S$, identificada como capítulo IX, do livro $4^{\circ}$, com um conteúdo importante para compreender-se em qual ponto do projeto originário das Instituições políticas se encerra aquele que ele chama de "pequeno tratado", valendo, para isto, a transcrição da passagem:

Depois de haver estabelecido os verdadeiros princípios do direito político e ter-me esforçado por fundar o Estado em sua base, ainda restaria ampará-lo por suas relações externas, o que compreenderia o direito das gentes, o comércio, o direito da guerra e as conquistas, o direito público, as ligas, as negociações, os tratados, etc. Tudo isso, porém, forma um novo projeto muito vasto para as minhas curtas vistas, e eu deveria fixá-las sempre mais perto de mim (OC III, Du contrat social, 1964, p. 470).

Vale observar pela transcrição seguinte - antes de comentar esse fragmento acima do final do Contrato social - o teor dos cinco $\S \S$ das páginas do Emílio ou da educação, os quais completam o texto precedente no sentido do que havia para fazer na

\begin{tabular}{|l|l|l|l|l|}
\hline Gevista Dialectus & Ano 8 & n. 15 & Agosto - Dezembro 2019 & p.54-71 \\
\hline
\end{tabular}


teoria de Rousseau que tinha sido elaborada no que toca às relações externas aos Estados sob o ponto de vista da gerência do direito. Essa passagem final do Emílio, que envolve, é claro, mais do que esse bloco de textos, reiterando o fragmento acima, diz que está tudo, retoricamente falando, por fazer da segunda parte da teoria rousseauniana ensaiada de ser feita, sendo complementar também dado ao fato de trazer um resumo do Contrato social, livro este que tinha vindo à lume um mês antes de ser publicado o segundo texto, chamado por Rousseau de "grande tratado". Veja-se que o extrato do Emílio guarda mesmo semelhança com a conclusão do Contrato social, embora agregue mais elementos que este texto inicial, explorando a questão em termos germinais, do objeto que é o direito, vendo-a em sentido mais amplo. Partindo da suposição de resolver o que implicava a primeira parte, escreve o genebrino:

Depois de considerarmos assim cada espécie de sociedade civil em si mesma, nós as compararemos para observar suas relações mútuas: umas grandes, outras pequenas; umas fortes, outras fracas; atacando-se, ofendendo-se, destruindo-se entre si; e nessa ação e reação contínua, fazendo mais miseráveis e custando a vida de mais homens do que se tivessem conservado sua liberdade primitiva. Não examinaremos se se fez de mais ou de menos na instituição social; se os indivíduos submetidos às leis e aos homens enquanto as sociedades guardam entre si a independência da natureza, não ficam expostos aos males dos dois Estados, sem ter as vantagens, e se não seria melhor não haver várias. Não é este Estado misto que participava de ambos e que não garante nem um nem outro "que não permite nem estar preparado em tempo de guerra nem seguro em tempo de paz?" Não é esta associação parcial e imperfeita que produz a tirania e a guerra? E não são a tirania e a guerra os maiores flagelos da humanidade? (OC IV, Émile ou de l'éducation, 1969, p. 848).

Examinaremos enfim a espécie de remédio que buscaram para tais inconvenientes mediante ligas e confederações, que, deixando cada Estado seu senhor internamente, o armam externamente contra todo agressor injusto. Procuraremos ver como se pode estabelecer uma boa associação federativa, o que a torna duradoura, e até que ponto se pode estender o direito de confederação, sem prejudicar o da soberania. (Idem, p. 848).

O abade de São Pedro propusera uma associação de todos os estados da Europa para a manutenção de uma paz perpétua. Essa associação era praticável? E, supondo-se que fosse estabelecida, fora de se presumir que teria durado? Tais pesquisas levam-nos diretamente a todas as questões de direito público que podem acabar de esclarecer as de direito político. (Idem, p. 848-849).

Poremos finalmente os verdadeiros princípios do direito da guerra e examinaremos porque Grotius, e os outros, dele não deram senão falsos princípios. (Idem, p. 849).

Não ficarei espantado se, em meio a nossos raciocínios, meu jovem, que tem bom senso, me disser, interrompendo-me: É de crer-se que construímos nosso edifício com madeira, e não com homens, a tal ponto ajustamos com precisão

\begin{tabular}{|l|l|l|l|l|}
\hline Q Povista Dialectus & Ano 8 & n. 15 & Agosto - Dezembro 2019 & p.54-71 \\
\hline
\end{tabular}


todas as peças à regra! É verdade, meu amigo, mas pensai em que o direito não se dobra às paixões dos homens, e que se tratava entre nós de estabelecer os verdadeiros princípios do direito político. Agora que nossos alicerces estão colocados, vinde examinar o que os homens construíram em cima, e vereis belas coisas! (Idem, p. 849).

Este grande fragmento abre espaço, assim, para chegarmos, até, noutros pequenos escritos fragmentários restantes, além de passagens de textos preparatórios, de certo modo, ao Contrato, mas que alimentam, de forma introdutória, o debate em torno da segunda parte das Instituições políticas, que foram, reitere-se, deixada de lado no decorrer do caminho. Esse é o caso do Discurso sobre a economia política (1758), antes conhecido como o verbete "economia" (moral ou política), do volume V da Enciclopédia diderotiana, publicado em 1755, que pensa, além de definir a "vontade geral" pela primeira vez enquanto base do Estado, questões como: subsistência dos cidadãos, circulação de mercadorias, finanças públicas, desenvolvimento da economia defendendo sobretudo a agricultura, estratégias para cobrar racionalmente impostos, etc. Rousseau entende que: "Não basta ter cidadãos e protegê-los. Necessário cuidar de sua subsistência. Atender às necessidades públicas é uma decorrência evidente da vontade geral. E o terceiro dever essencial do governo" (OC III, Discours sur l'economie politique, 1964, p. 262).

Apontando para a direção que vai levar seu argumento, Rousseau indica aquela que acredita ser a máxima mais importante da administração pública das finanças: "Empenhar-se muito mais em prevenir as necessidades do que em aumentar a receita" (Idem, p. 266). Seriam as necessidades inúteis, as superfluidades, que tirariam a paz, e encerrariam a tranquilidade, aumentando, ao final, as despesas do Estado, criando as necessidades de conquistas, comprometendo a soberania, etc. Em verdade, por isso é melhor manter-se a vida simples, distante dos requintes: “O Estado algumas vezes lucra em se fazer passar por rico, e essa riqueza aparente lhe é no fundo mais onerosa do que seria a própria pobreza" (Idem, p. 267).

Com as passagens de Rousseau, aquela do final do Contrato, e a outra, do final do Emílio, podemos, agora, recolocar a pergunta inicial: existe uma reflexão sobre o direito internacional no pensamento de Rousseau? Enquanto algo pleno e sistematizado está evidente que não! Ambos os escritos sinalizam que o filósofo de Genebra se interessou em tratar sobre o problema da sociedade de direito criando os princípios do direito político sob os quais buscou assentar o Estado enquanto uma

\begin{tabular}{|l|l|l|l|l|}
\hline Q Revista Dialectus & Ano 8 & n. 15 & Agosto - Dezembro 2019 & p.54-71 \\
\hline
\end{tabular}


criação humana, regulando a ordem civil, estabelecendo a paz, a justiça, e a liberdade. Se há uma lacuna aqui é na própria escrita de Rousseau, o qual não aborda exaustivamente o tema das relações internacionais, indispondo-se também em se assumir enquanto um pensador sistemático, tradicional, convencional. E não porque o julgue de pouca importância, pois Rousseau reconhece, no Emílio, que as questões ligadas ao direito no sentido mais amplo, global, universal, podem ajudar, em sendo discutidas, para se resolver problemas pendentes do direito político. Não é uma falta dos pesquisadores, portanto, não se aterem largamente a este assunto em seus estudos à medida que a discussão não foi rigorosamente articulada e sistematizada.

O foco de Rousseau esteve direcionado principalmente em pensar, no Contrato social, a problemática da política interna sob o ponto de vista do direito, trazendo a crítica ao direito positivo, crítica esta que termina com a proposição dos princípios do direito político, extraindo a referência ideal, aliás, do direito de natureza. Parte do projeto teórico rousseauniano, grosso modo, não foi levado adiante de forma plena, no qual se inseria a especulação verticalizada em torno das relações políticas externas, envolvendo isto os vários aspectos que dizem respeito ao direito neste plano, conforme a reflexão final do Contrato que se refere ao compromisso com um novo objeto de estudo que se faz demasiado amplo.

$\mathrm{Se}$, em um primeiro momento, este fragmento retira a chance de pensar-se que existe esta reflexão em Rousseau, ou que o filósofo tem-na em pouca conta, precisamos considerar sua referência, nos fragmentos citados, mas dos dois livros, ao Estado, que se funda nos princípios do direito político, Estado este marcado pela legitimidade no plano do poder, o qual encontra sustentação naqueles que trazem ao homem a liberdade, retirando-o do seu ambiente de conflito, do seu estado de guerra produzido, após abandonar a paz do mundo natural.

Considerando um pouco mais a questão do Estado, a partir da conclusão do Contrato, cabe dizer que tivemos o estabelecimento desta instituição já naquele momento em que a discussão se desenrolava no plano factual e histórico, sendo o engenho dessa dita forma, mesmo que se tratasse de uma empresa hipotética. Essa instituição que definia os contornos da França setecentista, marcada pela presença do absolutismo monárquico e pelo despotismo religioso, exercido pela igreja católica, definindo a unidade do poder, era claramente, entretanto, avaliada, posta em discussão, no que tange à sua legitimidade, dada à natureza do poder político que a informava.

\begin{tabular}{|l|l|l|l|l|}
\hline Govista Dialectus & Ano 8 & n. 15 & Agosto - Dezembro 2019 & p.54-71 \\
\hline
\end{tabular}


Essa mantinha-se amparada no exercício da conduta arbitrária, da força, da violência, contando com o direito positivo, identificado como direito terreno por um nome importante da ciência jurídica de hoje, que o justifica, legitimando-o, ainda que não se trate de algo legítimo; pois precisaria, para sê-lo, salvaguardar o direito natural, do qual decorre o reconhecimento da igualdade moral e política, da liberdade, direitos estes desfrutados pelo homem em seu período áureo.

O Estado à que se refere o genebrino no capítulo final do Contrato em seu único parágrafo é o que surge quando ele se afixa na perspectiva do dever ser da política, tendo já findado seu diagnóstico acerca da fonte geradora dos males morais, encaminhando-se para dar forma ao estado de direito recorrendo aos princípios teóricos e abstratos, mas de "direito político". É certo que não se trata aí de uma quimera, de um sonho, de uma utopia, mas do esforço de conceder legitimidade ao poder político criador desta tão festejada instituição, apresentando ou fornecendo as bases de sua sustentação teórica e prática, que pareceriam ser mais convincentes. Se depois vai surgir um homem inclinado a desacreditar da política, aqui não é este, ainda, o caso posto exatamente em questão. Tamanho otimismo poucas vezes foi revelado por um pensador cuja fé no homem é tanta, neste momento, que nele ressona o eco de Platão; este personagem, este homem, ilustre da Antiguidade, convertendo-se em cidadão exemplar para os gregos, consegue compreender o verdadeiro sentido do Estado, por conta das luzes luminosas da razão que o auxiliam. E o homem impulsionado, no caso de Rousseau, pela lei natural, lei esta que vem dirigir sua vontade, mas que se substantiva, objetivando-se, consumando-se, pois, enquanto vontade geral, passando a atender, finalmente, aos interesses do bem comum, é que significa a meta mesma de seu estabelecimento.

Tudo isso é definido encontrando o apoio nos chamados princípios do direito político que requereriam um tratamento aqui mais demorado. Mas basicamente esse Instituição exemplar, modelar, emerge do pacto social legítimo, garantindo a vigência do poder político respaldado no consentimento, excluindo, portanto, a arbitrariedade, tendo um fundamento abstrato, ideal, metafísico. Com este, forma-se o "corpo político" que conta, essencialmente, com a figura do soberano, e a ele se apresentando enquanto espécie de subordinado, de empregado, fazendo-se daí homem prático, gestor, administrador, o próprio governante. O primeiro surge - apesar de constituir-se enquanto povo - como indivíduo, mas agora mais do que um simples

\begin{tabular}{|l|l|l|l|l|}
\hline Q Rovista Dialectus & Ano 8 & n. 15 & Agosto-Dezembro 2019 & p. $54-71$ \\
\hline
\end{tabular}


homem, e sim um cidadão, no momento em que é praticado o ato de "alienação da vontade" pelo qual vem com seus congêneres, estabelecendo o corpo político, ser sujeito de suas próprias leis, engendrando a liberdade moral e convencional que antes lhe era desconhecida. O convênio, o pacto associativo, se propunha resolver o problema fundamental, basilar, encontrando as suas cláusulas unidas nesta apenas, a saber, a alienação completa de cada contratante, com todos seus direitos, à comunidade no geral, que é o seguinte: "encontrar uma forma de associação que defenda e proteja a pessoa e os bens de cada associado com toda a força comum, e pela qual cada um, unindo-se a todos, só obedece contudo a si mesmo, permanecendo tão livre quanto antes" (OC III, Du contrat social, 1964, p. 360). Ao encontrar êxito, este ato de fundação, que será seguido dos desdobramentos e relações adicionais que lhe são inerentes, garante, finalmente, a unidade, a paz, a sintonia entre os homens nas relações desencadeadas no seio do Estado, no interior de seus muros, viabilizando, portanto, a governança. E desta relação no Estado, na sociedade civil, entre os membros do convênio, pautando-se pelas cláusulas essenciais estabelecidas, assegurando o triunfo internamente, enquanto um exercício teórico, no mínimo, de pensamento, de reflexão, é que Rousseau acreditava ter dado conta, ter consumado, chegando ao termo conclusivo de seu "pequeno" escrito, o renomado Contrato social ou princípios do direito político, acreditando contribuir com a vida, do modo mais justo que fosse efetivamente possível, aos agentes autônomos do convênio.

III

Para além de saber que o genebrino tinha um projeto teórico maior, como já dissemos, para o qual pensava mobilizar todas suas forças e habilidades, mas que terminou abandonando, o leitor precisa ter ciência que o seu ponto de partida foi meditar sobre as relações humanas e jurídicas que se estabeleciam internamente na comunidade. Agora, mesmo este tipo de discussão deixa claro que estava na sua agenda refletir em torno da relação entre os Estados à medida que os acontecimentos históricos da época moderna, incluindo o período iluminista, também cobravam por isso. Pensando naquele conceito, na ideia de Estado exposta ao final do Contrato, e nas questões que lhes são afins, e indo-se ao resumo transcrito do Emílio, implementa-se essa compreensão e percebe-se nuances do problema, lembrando-se de passagens de textos e outros escritos fragmentários que sobraram, chegando até nós, retratando aspectos do direito internacional, conectando-se à segunda parte das Instituições

\begin{tabular}{|l|l|l|l|l|}
\hline Govista Dialectus & Ano 8 & n. 15 & Agosto-Dezembro 2019 & p. 54-71
\end{tabular}


políticas. Um destes textos famosos que sobreviveram foi a primeira versão do Contrato social, livro este também conhecido como Manuscrito de Genebra (1761), cuja parte de grande importância, no tocante a nosso presente assunto, é seu segundo capítulo intitulado Da sociedade geral do gênero humano. Aqui o que salta aos olhos é a oposição que Rousseau assume, no seu pensamento, em relação às ideias de Grotius e Hobbes, dentre outros, que insistem em considerar que a guerra é o natural mostrando o interesse que eles têm em infringirem os direitos, favorecendo a violência e o despotismo. Foi preciso que o homem, na opinião de Rousseau, deixasse o estado de natureza para chegar a um patamar mais elevado de existência, mas a felicidade da idade de ouro, ponto intermediário do seu percurso, só lhe pode na verdade, trazendo ele aqui uma nuance do seu olhar negativo e pessimista, ser coisa estranha, pondo-o diante de um impasse:

\footnotetext{
Assim, a voz gentil da natureza não é mais um guia infalível para nós, como não é uma situação desejável a independência que dela recebemos. Perdemos definitivamente a paz e a inocência antes de apreciarmos as suas delícias. Desconhecida pelos homens ignorantes dos primeiros tempos, perdida para os homens esclarecidos dos tempos modernos, a vida feliz da idade de ouro sempre foi uma situação estranha à condição humana, ou porque não foi reconhecida quando os humanos poderiam tê-la gozado ou porque já tinha sido perdida quando eles a poderiam reconhecer (OC III, Manuscrit de Genève, 1964, p. 283).
}

Passou a representar um ditame para o homem deixar o estado de guerra finalmente, visto que era o estado por ele vivido na sociedade corrompida, ainda que fosse um equívoco de Hobbes julgar tal estado enquanto uma herança da natureza, a exemplo do que pensava Grotius: "o erro cometido por Hobbes [...] não foi o de estabelecer o estado de guerra entre homens independentes que se tornavam sociáveis, mas o de supor que esse estado seja natural à espécie, e considerá-lo como causa dos vícios de que é apenas o efeito" (Idem, p. 288).

\section{IV}

Ao nos reportarmos aos Princípios do direito da guerra, outro texto encontrado daqueles que iriam compor a sequência das Instituições políticas, reunimos mais elementos para pensar e acreditar que o ideal de Rousseau estava calcado em ter a ideia da unidade natural enquanto referência, recusando por isso o ponto de vista hobbesiano insistindo que é da natureza humana a conduta pacífica, a benevolência, a

\begin{tabular}{|l|l|l|l|l|}
\hline Q Rovista Dialectus & Ano 8 & n. 15 & Agosto - Dezembro 2019 & p.54-71 \\
\hline
\end{tabular}


inclinação para se compadecer com aquele que sofre, a sentir piedade, precisando, ao final, de pouco para se conservar, vivendo solitariamente, tendo paixões reduzidas:

Eu já disse e não custa repetir; o erro de Hobbes e dos filósofos é confundir o homem natural com o homem que eles têm sob os olhos e de transportar para um sistema um homem que só pode subsistir num outro. $\mathrm{O}$ homem quer seu bem-estar e tudo o que pode contribuir para tal, isso é incontestável. Mas, naturalmente, o bem-estar do homem se limita ao necessário físico: pois, quando ele tem a alma sã e quando seu corpo não sofre, o que lhe falta para ser feliz, conforme sua constituição? Aquele que não tem nada deseja pouca coisa, aquele que comanda ninguém tem pouca ambição. Mas o supérfluo desperta a cobiça: quanto mais se obtém, mais se deseja. Aquele que tem muito quer tudo, e a loucura da monarquia universal nunca atormentou senão o coração de um grande rei. Eis a marcha da natureza: eis o desenvolvimento das paixões. Um filósofo superficial observa as almas cem vezes remodeladas e fermentadas no levedo da sociedade e crê ter observado o homem. Mas, para bem conhecê-lo, é preciso saber discernir a gradação natural de seus sentimentos e não é nunca entre os habitantes de uma grande cidade que é preciso procurar o primeiro traço da natureza impresso no coração humano (ROUSSEAU, Jean-Jacques. "Princípios do direito da guerra". Transformação, v. 34, n.1, 2011, p. 158). ${ }^{2}$

Com este entendimento de que as paixões humanas são serenas nos começos, de que as necessidades são limitadas, de que, antes de se associar aos outros homens, o ser humano é pacífico, tímido, inexistindo guerra geral de homem a homem, não tendo sido este feito para se destruir mutuamente, Rousseau buscou garantir o direito desse, visando assegurar-lhe a justiça, com o estabelecimento do estado de direito político. Até aqui o problema é pensado por Rousseau tendo em conta o Estado apreendido interna e isoladamente com a retirada de sua pátria de adoção ou aquele que é objeto teórico- reflexivo no estado de natureza. Para avançar a reflexão em torno ao direito das gentes, ao direito dos povos, ao direito internacional, temos de considerar a existência de países e a relação entre estes, os conflitos que se estabelecem, enfim, neste âmbito mais amplo. Ora, daí cabe voltar ao Emílio, na parte transcrita e analisada, pois este texto introduz o problema, em primeiro lugar, de que os Estados se conservaram no

2 Este texto sendo o mesmo "O estado de guerra nascido do estado social", juntamente com o "Fragmento sobre a guerra", teve uma primeira tradução brasileira feita por Sérgio Bath publicada pela Editora UNB em 2003. Optei por referir esta, aparecida em 2011, realizada por Evaldo Becker, com base na de Bruno Bernardi e Gabriela Silvestrini publicada na França, pela Vrin em 2008, e citada na bibliografia final do artigo. Fiz essa escolha visto que esta primeira tradução está mais próxima daquela que figura no volume III das Oeuvres Complètes de Rousseau, da edição da Pléiade, que se tornou objeto de correção a partir dos estudos que estão sendo realizados na França por estes outros editores, propondo uma outra compreensão sobre os achados. Esta correção diz mais respeito, aqui pelo menos, à distribuição dos parágrafos do que propriamente ao conteúdo de modo que se pode consultar no Tomo III, da Pléiade, "Que l'etat de guerre nait de l'etat social", inserido nos Ecrits sur l'Abbé de Saint-Pierre, à medida que se estiver impossibilitado de acessar o texto em francês da Vrin.

\begin{tabular}{|c|c|c|c|c|}
\hline Rovita Aialectus & Ano 8 & n. 15 & Agosto - Dezembro 2019 & p. $54-71$ \\
\hline
\end{tabular}


estado de natureza na relação entre eles. Temos de averiguar qual é a posição de Rousseau neste caso, a partir dos Princípios do direito da guerra, se é possível a conquista desta relação pacífica chegando no plano das relações jurídicas, internacionalmente falando.

Vale observar que antes de se aprofundar no terreno jurídico, visando retratar o direito da guerra, nos Princípios do direito da guerra, o pensador genebrino, desejando se fazer inovador, questiona a distância que há entre as teorias filosóficas e o mundo mesmo. Propondo uma reviravolta radical com o caráter crítico do seu discurso, Rousseau problematiza a posição dos jurisconsultos e filósofos convencionais sugerindo talvez que a discussão neste outro nível supõe outras dificuldades:

\begin{abstract}
Eu abro os livros de direito e de moral, escuto os sábios e os jurisconsultos e, impressionado por seus discursos insinuantes, deploro as misérias da natureza, admiro a paz e a justiça estabelecidas pela ordem civil, bendigo a sabedoria das instituições públicas e me consolo de ser homem vendo-me como cidadão. Bem instruído de meus deveres e de minha felicidade, fecho os livros, saio da classe e olho ao redor de mim: vejo povos infortunados gemendo sob o jugo de ferro, o gênero humano esmagado por um punhado de opressores, uma multidão sobrecarregada de trabalho e faminta por pão, da qual o rico bebe em paz o sangue e lágrimas, e em todo o lugar o forte armado contra o fraco do temível poder das leis. Tudo isso se faz pacificamente e sem resistência: é a tranquilidade dos companheiros de Ulisses trancados na caverna do Ciclope, esperando para serem devorados. É preciso gemer e calar-se (Idem, p. 154).
\end{abstract}

Rousseau avança apresentando uma visão pessimista sobre o quadro que pode se inaugurar, mas sem esconder sua desconformidade e sua inclinação para colocar os problemas, como se tratasse de um dever de humanidade:

\begin{abstract}
As entranhas de que homem não ficariam comovidas com esses tristes objetos; mas não é mais permitido ser homem e pleitear a causa da humanidade. A justiça e a verdade devem ser dobradas ao interesse dos mais poderosos, é a regra. $\mathrm{O}$ povo não dá nem pensões, nem empregos, nem cátedras, nem vagas nas academias; em virtude de que protegê-lo-íamos? Príncipes magnânimos de quem esperamos tudo, falo em nome do corpo literário. Oprimi o povo com a consciência tranquila; e somente de vós que esperamos tudo e o povo nunca será bom para nada (Idem, ibidem).
\end{abstract}

Fechando a relação com a escrita dos Princípios do direito da guerra, com a análise inicial de suas ideias, vemos que Rousseau é desesperançoso, negativo, pessimista, quanto a relação pacífica entre os diferentes países, vendo-os gozarem, desfrutarem, de liberdade natural, agora sim, como as concebe Hobbes, uns em face dos

\begin{tabular}{|l|l|l|l|l|}
\hline Q Revista Dialectus & Ano 8 & n. 15 & Agosto - Dezembro 2019 & p. 54 - 71 \\
\hline
\end{tabular}


outros, tendo-se o estado civil somente na relação de homem a homem, formando, no quando geral, uma condição mista muito desfavorável:

A primeira coisa que eu observo, ao considerar a posição do gênero humano, é uma contradição manifesta em sua constituição, que a torna sempre vacilante. De homem a homem, nós vivemos no estado civil e submissos às leis. De povo a povo, cada um goza a liberdade natural; o que no fundo torna nossa situação pior do que se essas distinções fossem desconhecidas. Pois, vivendo ao mesmo tempo na ordem social e no estado de natureza, estamos submetidos aos inconvenientes de um e de outro, sem encontrar segurança em nenhum dos dois. A perfeição da ordem social consiste, é verdade, no concurso da força e da lei: mas é preciso, para isso, que a lei dirija a força, ao passo que nas ideias de independência absoluta dos príncipes somente a força sozinha, falando aos cidadãos sob o nome de lei e aos estrangeiros sob o nome de razão de Estado, tira destes o poder e dos outros a vontade de resistir, de sorte que o vão nome de justiça serve em toda parte apenas de salvaguarda à violência. Quanto ao que se chama comumente de direito dos povos, é certo que, à falta de sanção, suas leis, não são senão quimeras mais fracas ainda do que a lei da natureza, esta fala pelo menos ao coração dos particulares, ao passo que o direito dos povos, não tendo outra garantia senão a utilidade daquele que a ele se submete, suas decisões só são respeitadas enquanto o interesse as confirma. Na condição mista em que nos encontramos, a qualquer dos dois sistemas que dermos a preferência, fazendo muito ou muito pouco não fazemos nada e somos colocados no pior estado em que pudéssemos nos encontrar. Aí está, parece-me, a verdadeira origem das calamidades públicas (Idem, p. 154-155).

$\mathrm{V}$

Mantendo-me na leitura do fragmento que transcrevi da parte final do Emílio ou da educação, termino com a referência à reflexão de Rousseau, introduzida neste escrito, ao texto Extrato e julgamento do projeto de paz perpétua do Abade de Sainte-Pierre (1755-1756), outro dos poucos trabalhos relacionados ao nosso assunto, feito com base neste pensador fundamental na discussão sobre o tema da paz no século XVIII. Trata-se de um breve texto de Rousseau dividido em duas partes, o Extrato e o Julgamento, sendo que o filósofo ora resume as ideias do Abade, ora as analisa criticamente, considerando-as difíceis de serem implementadas. Rousseau o contempla, como dissemos, na passagem em análise do Emílio. Aqui ele nos dá a conhecer a ideia da formação da comunidade de países da Europa, a de criação de ligas, de confederações, enquanto forma de retirar os Estados do estado de natureza, na relação entre eles, visando a conquista da paz planetária. Assim, seria estabelecida a regulamentação das relações, do intercâmbio, de modo a assegurar a coesão, o bom entendimento, sem romper com a soberania.

\begin{tabular}{|l|l|l|l|l|}
\hline Govista Dialectus & Ano 8 & n. 15 & Agosto - Dezembro 2019 & p. 54 - 71 \\
\hline
\end{tabular}


Rousseau toma para si, em partes, as ideias do Abade de Saint-Pierre. Observando o Extrato pensa-se que o especulador genebrino vê nos anseios do Abade só uma utopia irrealizável, pois este parece pôr-se a sonhar ao ver, enquanto algo fantasioso, a unidade humana sendo efetivamente estabelecida:

Com os olhos da imaginação vejo todos os homens vinculados pelos laços do amor. Convoco mentalmente uma fraternidade gentil e pacífica, vivendo em permanente harmonia, guiados todos pelos mesmos princípios, encontrando cada um a sua felicidade na felicidade geral. E ao deter-me neste quadro tocante a ideia de uma felicidade imaginária me dará por alguns instantes a falsa sensação do gozo da felicidade real (OC III, Écrits sur l'Abbé de SaintPierre (Extrait du projet), 1964, p. 563).

A impressão inicial que se tem leva a pensar que Rousseau é absolutamente pessimista quanto ao plano teórico do Abade, mas se passamos a observar a segunda parte de seu escrito, notamos o crédito que ele deposita no autor. Fiquemos então com as considerações de seu Julgamento:

O esquema de uma paz duradoura foi dentre todos, o mais digno de fascinar um homem de princípios elevados. Assim, de todos os temas que mereceram o empenho do Abade de Saint-Pierre foi aquele por mais tempo o interessou e o que seguiu com maior obstinação. É difícil, na verdade, qualificar de outra forma o zelo missionário que nunca o abandonou nessa empresa, a despeito da clara impossibilidade do seu sucesso, da ridicularização que lhe trouxe a cada dia e das objeções que precisou suportar continuamente. Parecia que o seu espírito bem equilibrado, mirando exclusivamente o bem público, o levou a orientar sua devoção a uma causa só pela sua utilidade, sem nunca atemorizar-se com as dificuldades, e sem pensar em termos de interesse pessoal (OC III, Écrits sur l'Abbé de Saint-Pierre (Julgemen), 1964, p. 591).

Perfeitamente cônscio de que se tratava de algo para ainda realizar-se, completa seu pensamento Rousseau:

Diria que se alguma verdade moral já foi algum dia demonstrada, foi a utilidade deste projeto - nacional não menos do que internacional. As vantagens trazidas pela sua execução a cada príncipe, a cada nação e ao conjunto da Europa são imensas, claras e incontestáveis; e nada poderia ser mais sólido ou mais preciso do que os argumentos empregados pelo autor para demonstrá-las. Instituída por um só dia a sua comunidade europeia certamente duraria para sempre, tal a força com que a experiência convenceria os homens de que encontrariam vantagem para si na vantagem decorrente para todos. Não obstante, os mesmos príncipes que a defenderiam com toda a sua força se ela existisse, a resistiriam com igual empenho a qualquer proposta de criá-la. Infalivelmente criariam obstáculos ao seu caminho como o fariam se já existisse, e se buscasse a sua eliminação. Assim, o livro de Saint-Pierre sobre Uma paz perpétua parece incapaz de fundá-la e desnecessário para mantê-la. 'Trata-se, portanto, de um sonho vazio’ - será o veredito do leitor impaciente. Mas, não: é uma obra de julgamento sólido, que tem para nós a maior importância (Idem, ibidem).

\begin{tabular}{|l|l|l|l|l|}
\hline Q Rovista Dialectus & Ano 8 & n. 15 & Agosto - Dezembro 2019 & p.54-71 \\
\hline
\end{tabular}


Tanto fica, com essas considerações dialogais, ambivalentes, justificado para outra oportunidade, em suma, explorar as nuances da reflexão de Rousseau neste presente texto, alargando nosso entendimento sobre suas ideias no que tange ao direito internacional, como é importante conhecer os livros de Charles Irinée Castel de SaintPierre, o chamado Abade de Saint-Pierre.

O esforço trazendo essas noções básicas, passando pelos diferentes escritos fragmentários de Rousseau encontrados, visando servir enquanto um tipo de rastreamento para o tema proposto, é para facilitar e garantir a continuidade do trabalho, numa posterior retomada e aprofundamento, em mais de um capítulo, considerando a produção que já vem sendo aos poucos realizada, não tendo aqui, portanto, uma pretensão de originalidade. $^{3}$

Com todas essas referências, incluindo às finais, com base na contribuição de Saint-Pierre, fica claro que levar adiante, aprofundar tal estudo, é perfeitamente plausível e necessário, devido a atualidade da problemática proposta.

\section{REFERÊNCIAS:}

BLOOM, Allan. "Jean-Jacques Rousseau". In.: Leo Strauss y Joseph Cropsey (compiladores). Historia de la filosofia política. México: Fondo de Cultura Económica, 2001, p. 529-548.

FONSECA Jr, Gelson. As múltiplas dimensões do pensamento de Rousseau (Prefácio). In.: ROUSSEAU, Jean-Jacques. Rousseau e as relações internacionais. Trad. de Sérgio Bath. São Paulo: Imprensa Oficial do Estado, 2003, p. IX-LXIV.

GAGNEBIN, B. Notice. In.: ROUSSEAU, Jean-Jacques. Oeuvres complètes. Paris: Bibliotèque de la Pléiade, 1964, t. III, p. 1899.

HOFFMAN, Stanley. Rousseau sobre a guerra e a paz. Trad. de Carlos Henrique Canesin. Videre, Vol. 2, n. 3, 2010, p. 27-64.

MARQUES, José Oscar de Almeida. Contrato e confederações; notas sobre o papel das relações internacionais no pensamento político de Jean-Jacques Rousseau. In.: SILVA, Genildo Ferreira da (org.). Rousseau e o iluminismo. Salvador, BA: Arcádia, 2009, p. 33-43.

Agradeço a oportunidade de ter podido explaná-las no "I Workshop de Teorias da Justiça: o Direito Internacional em Debate" no dia 07/12/2018 na Univ. Est. de Londrina, contando com a promoção do "Grupo de Pesquisa em Teorias da Justiça", instalado no CLCH, Dep. de Fil., ficando liberado para divulgá-las aqui.

\begin{tabular}{|l|l|l|l|l|}
\hline Qevista Dialectus & Ano 8 & n. 15 & Agosto - Dezembro 2019 & p.54-71 \\
\hline
\end{tabular}


NODARI, Paulo C. Rousseau e a paz. Veritas, Porto Alegre, Vol. 56, n. 3, 2011, p. 167-184.

PETRUCCIANI, Stefano. Modelos de filosofia política. Trad. de José Raimundo Vidigal. São Paulo: Paulus, 2014.

ROMANO, Roberto. Pensamento e monstruosidade. Revista USP, São Paulo, n. 50, p. 210-220, junho/agosto 2001.

ROUSSEAU, Jean-Jacques. Principes du droit de la guerre. Texte établi par Bruno Bernardi et Gabriela Silvestrini. Annales de la Société J.-J. Rousseau, Genève, t. XLVI, p. 201-280, 2005.

. Principes du droit de la guerre. Ecrits sur la paix perpétuelle. Paris: Vrin, 2008.

Princípios do direito da guerra. Trad. de Evaldo Becker. Transformação, Marília, v. 34, n. 1, p. 149-172, 2011.

Tratado sobre a economia política; O estado de guerra nascido do estado social; Fragmentos sobre a guerra; Extrato e julgamento do projeto de paz perpétua de Abbé de Saint-Pierre; Sobre o contrato social (primeira versão) ou Ensaio sobre a forma da república conhecido como Manuscrito de Genebra; Projeto de constituição para a Córsega; Considerações sobre o governo da Polônia e a sua projetada reforma. In.:

Rousseau e as relações internacionais. Trad. de Sérgio Bath. São Paulo: Imprensa Oficial do Estado, 2003.

Discours sur l'origine et les fondements de l'inégalité parmi les hommes. Oeuvres completes. Paris: Gallimard, Bibliotèque de la Pléiade, 1964, t. III.

Discours sur l'économie politique. Oeuvres completes. Paris: Gallimard, Bibliotèque de la Pléiade, 1964, t. III.

Du contract social ou essai sur la forme de la republique (première version). Oeuvres completes. Paris: Gallimard, Bibliotèque de la Pléiade, 1964, t. III.

Du contrat social, ou les principes de les droit politique. Oeuvres completes. Paris: Gallimard, Bibliotèque de la Pléiade, 1964, t. III.

Écrits sur l'Abbé de Saint-Pierre. Oeuvres completes. Paris: Gallimard, Bibliotèque de la Pléiade, 1964, t. III.

Émile ou de l'éducation. Oeuvres completes. Paris: Gallimard, Bibliotèque de la Pléiade, 1969, t. IV.

RUZZA, Antonio. Rousseau e a moralidade republicana no contrato social. São Paulo: Annablume, 2010.

\begin{tabular}{|l|l|l|l|l|}
\hline Q Rovista Dialectus & Ano 8 & n. 15 & Agosto - Dezembro 2019 & p.54-71 \\
\hline
\end{tabular}


SANTANA, Jenifer Queila. Desafios internacionais para o Estado modelado por Rousseau. RICRI, Vol. 2, n. 4, p. 102-126.

SCHULTE-TENCKHOFF, Isabelle. Rousseau et le droit de gens. In.: BOULADAYOUB, Josiane et alii. Rousseau; anticipateur-retadataire. Québec: Les Presses de l’Université Laval; Paris: L'Harmattan, 2000, p. 153-160.

SERRA, Antonio T. Y. La guerra y la paz en Rousseau y Kant. Revista de Estudios Politicos, n. 8, 1979, p. 47-62.

VARGAS, Yves. Rousseau, les paysans et la monnaie. In.: BOULAD-AYOUB, Josiane et alii. Rousseau; anticipateur-retadataire. Québec: Les Presses de l'Université Laval; Paris: L'Harmattan, 2000, p. 163-172. 